\title{
Modelling Element of Chips in Rotary Milling by Experiment Planning Method
}

\author{
V.G. Shalamov \\ Federal State Autonomous Educational Institution of Higher \\ Education "South Ural State University (national research \\ university)" \\ Chelyabinsk, Russia \\ ShalamovVG@susu.ru
}

\author{
S.D. Smetanin \\ Federal State Autonomous Educational Institution of Higher \\ Education "South Ural State University (national research \\ university)" \\ Chelyabinsk, Russia \\ SmetaninSD@susu.ru
}

\author{
A.V. Plaksin \\ Federal State Autonomous Educational Institution of Higher \\ Education "South Ural State University (national research \\ university)" \\ Chelyabinsk, Russia \\ PlaksinAV@susu.ru
}

\begin{abstract}
Investigation results of modeling the influence of different parameters on the chip element length in rotary milling are presented. To highlight the significantly influencing factors, we used Plackett-Berman's plans. Evaluation of the adequacy of the regression equation was carried out according to the Fisher criterion. As a result, an adequate empirical mathematical model for determining the length of the chip element in the form of an algebraic polynomial is obtained
\end{abstract}

Keywords—rotary milling, chips, modelling, experimental planning method

\section{INTRODUCTION}

Today the most dynamically developing areas of modern production are additive technologies or layer-by-layer technologies that appeared in the late 1980s [1]. Their rapid development was promoted by a wide circulation of digital technologies in the field of designing, modeling, calculations and machining. And at present it is difficult to name the area of material production, where 3D printing technologies would not have been used to some extent. They allow speeding up $\mathrm{R} \& \mathrm{D}$ and solving the problems of preparation of production by an order of magnitude, and in a number of cases they are already actively used for production of finished products.

The quality of the final product, in addition to the production technology, depends on the model material. In this case, the use of various polymer materials, concrete, gypsum, wood fiber, polycarbonate and other nonmetallic materials makes it possible to basically create a model, a layout, a prototype to a certain extent close to the present detail. Using the same metal components, it is possible to get exactly "real" goods (mold blanks, special tools, original parts of aircraft, complex satellites that are difficult or impossible to obtain by casting or machining)
The main deterrent factors for the development of additive technologies are the lack of personnel, the high cost of the plants themselves and the metal initial components (powders). But along with the fact that the park of $3 \mathrm{D}$ printers for the production of metal products and the number of specialists is growing rapidly, the problem of the initial powders became more acute. This is due to the fact that a single nomenclature production requires a wide range of initial (often unique, special composition) powders in a small amount. The market can offer either a large amount of this powder or analogues of a close chemical composition, since the equipment for the production of powders has certain technological limitations - it is impossible to produce less than a certain amount, it is impossible to produce a powder of this particular chemical composition on this equipment, etc. Powder replacement analogue may require the conduct of long and costly tests, increasing the time and cost of manufacturing the final product. To solve this problem, it is important to create a technology for obtaining powder of a given shape and size. Methods for obtaining powders are characterized by energy consumption, purity, productivity, ranges of possible shapes and sizes, suitability for a given material, and other parameters. One of the methods for obtaining powders in the form of element chips is rotary cutting.

\section{The Model of ElEMENT ChIPS IN Rotary MiLling}

The research of the rotational cutting process showed its high efficiency $[2,3]$ when processing details of simple shape, highlighting the following advantages: high resistance of cutting elements due to the long length of the cutting edges, as well as the periodicity of cutting by each point of the cutting edge; reduction of cutting forces and temperature in the treatment zone by introducing additional motion into the process. When using this technology for grinding, the obtained chips do not undergo temperature transformations and in 
chemical composition it does not differ from the initial preform. Grinding technology is suitable for any solid materials.

The process of rotational milling in the production of element chips is different from the usual rotational milling when processing the surface of the workpiece with the design of the tool cutting unit: in addition to the smooth cutting element, it contains a gear, separating the cut off layer of the stock. Simulation of the dimensions and shape of the resulting chip element was carried out in [4]. The chip element has a complex shape (Fig. 1), which can be characterized by different sizes.
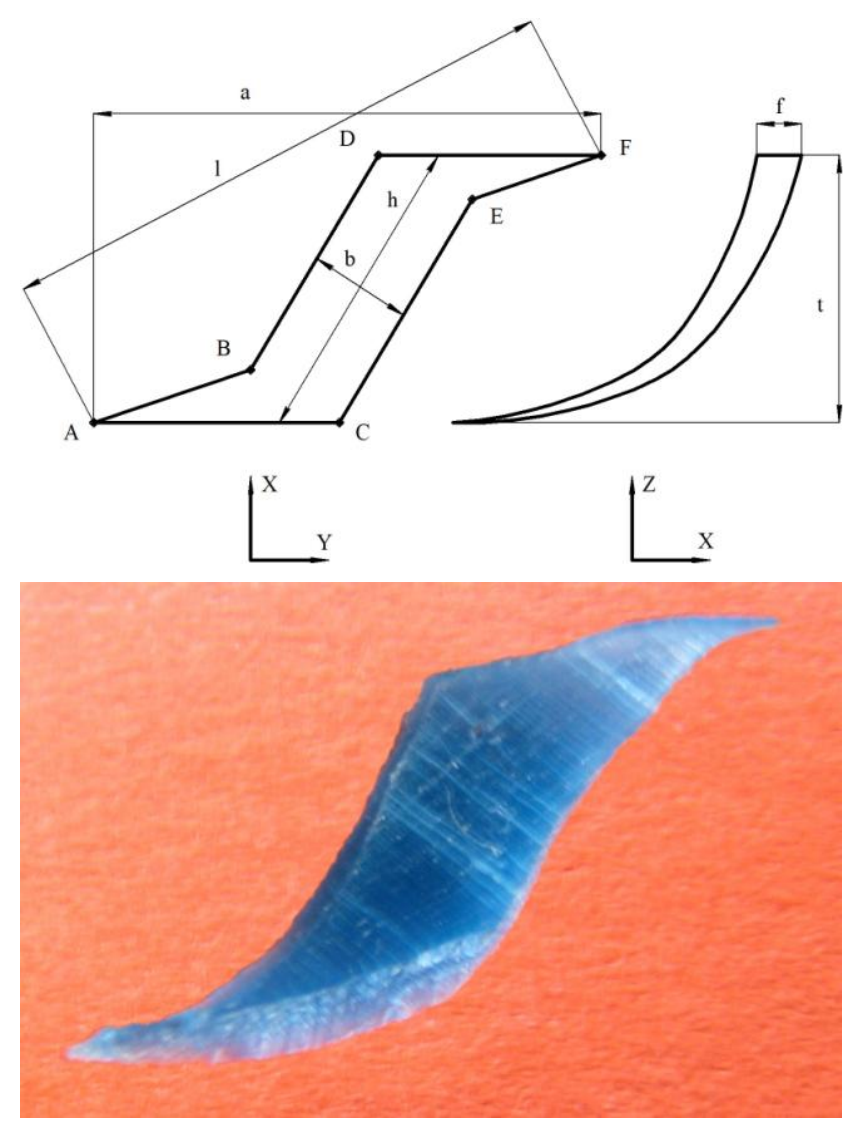

Fig. 1. Estimated (top) and experimental (bottom) shape of the chip element

The greatest difficulty is to ensure the length of the chip element 1 , so we take it as a controlled size. To determine the length of a chip element, we use the spatial coordinates of the boundary points $\mathrm{A}$ and $\mathrm{F}$ :

$$
\pi=\sqrt{X_{B}-X_{F}^{2}+Y_{B}-Y_{F}^{2}+Z_{B}-Z_{F}^{2}} .
$$

In accordance with the calculation scheme given in [4], the coordinates of the points under consideration are equal to:

$$
\left\{\begin{array}{l}
X_{A}=R \cos \left(\frac{u_{L}-u_{R}}{2}\right)+S\left(\frac{u_{L}-u_{R}}{2}\right) \\
Y_{A}=R \sin \left(\frac{u_{L}-u_{R}}{2}\right) \\
Z_{A}=r \cos \theta+L \sin \theta
\end{array} ;\right.
$$

$\int X_{F}=(L \cos 8-r \sin 8 \cos (\varphi))\left(\cos \pi \cos \left(\frac{k_{S} r\left(\varphi+\varphi_{t}\right)}{R}+\right.\right.$

$\left.\left.+\frac{u_{L}-u_{R}}{2}\right)-\sin \pi \sin \left(\frac{k_{S} r\left(\varphi+\varphi_{t}\right)}{R}+\frac{w_{L}-u_{R}}{2}\right)\right)-$

$-r \sin \left(\varphi+\varphi_{t}\right)\left(\sin \lambda \cos \left(\frac{k_{S} r\left(\varphi+\varphi_{t}\right)}{R}+\frac{u_{L}-u_{R}}{2}\right)+\right.$

$\left.+\cos \pi \sin \left(\frac{k_{S} r\left(\varphi+\varphi_{t}\right)}{R}+\frac{u_{L}-u_{R}}{2}\right)\right)+$

$+R \cos \left(\frac{k_{S} r\left(\varphi+\varphi_{t}\right)}{R}+\frac{w_{L}-w_{R}}{2}\right)+$

$\left\{+S\left(\frac{k_{S} r\left(\varphi+\varphi_{t}\right)}{R}+\frac{u_{L}-u_{R}}{2}\right)\right.$

$Y_{F}=(L \cos \theta-r \sin \theta \cos (\varphi))\left(\sin \pi \cos \left(\frac{k_{S} r\left(\varphi+\varphi_{t}\right)}{R}+\right.\right.$

$\left.+\frac{u_{L}-u_{R}}{2}\right)+\cos \pi \sin \left(\frac{k_{S} r\left(\varphi+\varphi_{t}\right)}{R}+\frac{u_{L}-u_{R}}{2}\right)+$

$+\sin \left(\varphi+\varphi_{t}\right) \cos \pi \cos \left(\frac{k_{S} r\left(\varphi+\varphi_{t}\right)}{R}+\frac{w_{L}-w_{R}}{2}\right)-$

$\left.-\sin \pi \sin \left(\frac{k_{S} r\left(\varphi+\varphi_{t}\right)}{R}+\frac{w_{L}-w_{R}}{2}\right)\right)+$

$+R \sin \left(\frac{k_{S} r\left(\varphi+\varphi_{t}\right)}{R}+\frac{w_{L}-w_{R}}{2}\right)$

$Z_{F}=r \cos \theta \cos \left(\varphi+\varphi_{t}\right)+L \sin \theta$

where $r$ - radius of the cutting element; $R$ - distance from the axis of rotation of the cutter to the axis of the cutting block; $L$ - displacement of the end of the cutting element relative to the axis of rotation of the cutting unit; $\varphi$ - angle of the tip of the teeth of the cutting element; $\varphi_{t}$ - contact angle of the cutting element with the workpiece; $\psi_{L}-$ angular position of the left end of the workpiece relative to the axis of the mill; $\psi_{R}$ - angular position of the right end face of the workpiece relative to the axis of the cutter; $S$ - feed per revolution of the mill; $\lambda$ - angle of inclination of main cutting edge; $\beta$ - angle of inclination of the axis of the cutting block relative to the surface to be treated; $k_{S}$ - coefficient of relative slippage of the cutting element over the workpiece. 


\section{ISOLATION OF SUBSTANTIALLY INFLUENCING FACTORS}

Thus, the process of rotary milling in the production of element chips is characterized by 11 parameters that affect the output characteristics of the process (in particular, the length of the chip element). Therefore, the mathematical model obtained, with all parameters taken into account, is difficult for analysis and control. At the same time, it is obvious that not all parameters are equivalent in terms of the degree of influence. We isolate the significantly influencing factors using the methods of experiment planning.

To isolate substantially influencing factors, one can use various methods and plans: factor ranking, variance analysis, saturated regular fractional factor plans, plans Plackett and Berman, random balance method, sequential screening experiments, etc. [5-8]. Although methods are auxiliary tools, they are important tools in the optimization and management of technological processes. They differ in the degree of objectivity, they have a different degree of elaboration, different computational complexity, laboriousness, accuracy of parameter estimation, etc. These conditions are not very important, since their main purpose is to isolate a relatively small number of influencing factors from a relatively large number of influencing factors. Then it will be possible to determine with sufficient accuracy the degree of their influence, using elementary plans of the first or second order.

We use Pluckett-Berman's plans to identify significant factors. To use them, the number of factors should not be very large (in work [8], plans are provided that provide up to 72 factors). Since the length of the chip element was obtained theoretically, it can be stated that all the factors determining the desired parameter are known. The random factors acting on the process of shaping the chip element are not taken into account. Their influence is manifested in the spread of this parameter and should be the subject of independent research. Therefore, according to the mathematical model obtained, the theoretical chip length is determined when the levels of factors determined by the Plackett-Berman plan are combined.

Table I shows the levels of factors affecting the length of the chip element in absolute and coded form and their values. Table II shows the planning matrix and the values of the coefficients of the resulting model. The calculated theoretical values of the length of the chip element are equal to $y_{1}=$ $39.234 ; y_{2}=27.401 ; y_{3}=13.238 ; y_{4}=11.077 ; y_{5}=43.313 ; y_{6}$ $=24.887 ; y_{7}=9.493 ; y_{8}=20.574 ; y_{9}=40.47 ; y_{10}=24.637 ; y_{11}$ $=16.173 ; y_{12}=12.153 ; y_{13}=19.877 ; y_{14}=22.689 ; y_{15}=$ $50.158 ; y_{16}=12.091$.

The number of experiments should be $\geq$ the number of coefficients of the planned model. Given that the PluckettBerman plans must have a multiple of 4 trials, a plan with 16 experiments was adopted. To the main variables $x_{1} \ldots x_{11} 4$ dummy variables $x_{12} \ldots x_{15}$ were added. They allow [8] to estimate the variance of observations without conducting repeated experiments, which is impossible with numerical simulation.
TABLE I. LEVELS OF FACTOR VARIATION

\begin{tabular}{|l|c|c|c|}
\hline \multicolumn{1}{|c|}{ Factor } & \multirow{2}{*}{ Code } & \multicolumn{2}{c|}{$\begin{array}{c}\text { Levels/ coded } \\
\text { value }\end{array}$} \\
\cline { 3 - 4 } & & $\begin{array}{c}\text { Upper } \\
\text { level }\end{array}$ & $\begin{array}{c}\text { Lover } \\
\text { level }\end{array}$ \\
\hline distance, $R$, mm & $x_{1}$ & $250 /+1$ & $75 /-1$ \\
\hline $\begin{array}{l}\text { radius of the cutting element, } \\
r, \text { mm }\end{array}$ & $x_{2}$ & $30 /+1$ & $20 /-1$ \\
\hline $\begin{array}{l}\text { offset of the end of the cutting } \\
\text { element, } L, \text { mm }\end{array}$ & $x_{3}$ & $20 /+1$ & $-15 /-1$ \\
\hline depth of cut, $t$, mm & $x_{4}$ & $5 /+1$ & $1 /-1$ \\
\hline feed per turn mill, $S$, mm/rev & $x_{5}$ & $2 /+1$ & $0.1 /-1$ \\
\hline $\begin{array}{l}\text { angle of rotation of the cutting } \\
\text { element, } \lambda, \text { deg }\end{array}$ & $x_{6}$ & $70 /+1$ & $10 /-1$ \\
\hline $\begin{array}{l}\text { angle of inclination of the } \\
\text { cutting element, } \beta, \text { deg }\end{array}$ & $x_{7}$ & $30 /+1$ & $1 /-1$ \\
\hline angle of tooth apex, $\varphi$, deg & $x_{8}$ & $7 /+1$ & $2 /-1$ \\
\hline $\begin{array}{l}\text { coefficient of slippage, } k_{S} \\
\text { position of the left end of the } \\
\text { workpiece, } \psi_{L}, \text { deg }\end{array}$ & $x_{9}$ & $2 /+1$ & $1 /-1$ \\
\hline $\begin{array}{l}\text { position of the right end of the } \\
\text { workpiece, } \psi\end{array}$, deg & $x_{10}$ & $45 /+1$ & $5 /-1$ \\
\hline
\end{tabular}

TABLE II. PluKETT-BERMAN PlAN FOR 16 EXPERIMENTS

\begin{tabular}{|c|c|c|c|c|c|c|c|c|c|c|c|c|c|c|c|}
\hline $\mathbf{N}$ & $x_{1}$ & $x_{2}$ & $x_{3}$ & $x_{4}$ & $\mathbf{x}_{5}$ & $x_{6}$ & $x_{7}$ & $x_{8}$ & $x_{9}$ & $x_{10}$ & $x_{11}$ & $x_{12}$ & $x_{13}$ & $x_{14}$ & $x_{15}$ \\
\hline 1 & + & + & + & + & - & + & - & + & + & - & - & + & - & - & - \\
\hline 2 & + & + & + & - & + & - & + & + & - & - & + & - & - & - & + \\
\hline 3 & + & + & - & + & - & + & + & - & - & + & - & - & - & + & + \\
\hline 4 & + & - & + & - & + & + & - & - & + & - & - & - & + & + & + \\
\hline 5 & - & + & - & + & + & - & - & + & - & - & - & + & + & + & + \\
\hline 6 & + & - & + & + & - & - & + & - & - & - & + & + & + & + & - \\
\hline 7 & - & + & + & - & - & + & - & - & - & + & + & + & + & - & + \\
\hline 8 & + & + & - & - & + & - & - & - & + & + & + & + & - & + & - \\
\hline 9 & + & - & - & + & - & - & - & + & + & + & + & - & + & - & + \\
\hline 10 & - & - & + & - & - & - & + & + & + & + & - & + & - & + & + \\
\hline 11 & - & + & - & - & - & + & + & + & + & - & + & - & + & + & - \\
\hline 12 & + & - & - & - & + & + & + & + & - & + & - & + & + & - & - \\
\hline 13 & - & - & - & + & + & + & + & - & + & - & + & + & - & - & + \\
\hline 14 & - & - & + & + & + & + & - & + & - & + & + & - & - & + & - \\
\hline 15 & - & + & + & + & + & - & + & - & + & + & - & - & + & - & - \\
\hline 16 & - & - & - & - & - & - & - & - & - & - & - & - & - & - & - \\
\hline$b_{i}$ & $\begin{array}{l}\hat{\infty} \\
\stackrel{n}{?} \\
?\end{array}$ & $\begin{array}{r}\tilde{n} \\
\text { ñ }\end{array}$ & 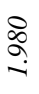 & $\frac{n}{n}$ & $\begin{array}{l}\text { ळे } \\
\text { - }\end{array}$ & ๙ֶ) & $\begin{array}{l}\sqrt{6} \\
6 \\
0 \\
1\end{array}$ & $\underset{\nabla}{\sigma}$ & $\begin{array}{l}\infty \\
n \\
n \\
n\end{array}$ & $\begin{array}{l}\stackrel{0}{t} \\
0 \\
0 \\
i\end{array}$ & $\frac{\overline{\mathfrak{v}}}{\mathfrak{n}}$ & $\frac{\pi}{2}$ & $\frac{a}{+}$ & $\frac{\tilde{z}}{i}$ & $\begin{array}{l}\infty \\
\tilde{N} \\
\tilde{n} \\
?\end{array}$ \\
\hline
\end{tabular}

Pluckett-Berman plans are orthogonal and normalized [6], so the calculation of the coefficients of the linear model can be performed (based on the method of least squares) by the expression: 


$$
b_{i}=\sum_{u=1}^{N} x_{i_{u}} y_{u} / N \text {. }
$$

The dispersion of experience $S_{y}^{2}$ can be estimated from the evaluation of dummy variables $x_{12}, x_{13}, x_{14}, x_{15}$ :

$$
S_{y}^{2}=N \sum_{j-1}^{N-k-1} b_{j}^{2} / N-k-1
$$

where $b_{j}$ - regression coefficient for the $\mathrm{j}$-th dummy factor; $k$ - number of real variables; $N$ - number of experiments in the plan.

The statistical significance of the coefficients is estimated from the value of the confidence interval:

$$
\Delta b_{i}=t_{\alpha ; f_{1}} S_{b_{i}},
$$

where $t_{\alpha ; f_{l}}$-Student's coefficient at the chosen level of significance and the number of degrees of freedom $f_{i} ; S_{b_{i}}-$ standard deviation of estimates of coefficients:

$$
\begin{gathered}
S_{b_{i}}^{2}=S_{y}^{2} / N \\
S_{y}^{2}=\frac{160.054^{2}+1.749^{2}+2.143^{2}+0.528^{2}}{16-11-1}=31.734 \\
t_{0.05 ; 4}=2.78 ; S_{b_{i}}^{2}=31.734 / 16=1.983 ; S_{b_{i}}=1.408 \\
\Delta b_{i}=2.78 \cdot 1.408=3.915
\end{gathered}
$$

The coefficient $b_{i}$ is statistically significant if the condition $b_{i} \geq \Delta b_{i}$ is observed (in Table II, statistically significant coefficients are shown in bold type). Excluding the statistically insignificant coefficients, we obtain the dependency of the length of the chip element ( $\tilde{y}$ calculated value of the output parameter):

$$
\tilde{y}=24.216+7.517 x_{4}-6.225 x_{6}+4.042 x_{8} .
$$

\section{A Mathematical Model for Calculating the Length OF THE ELEMENT CHIP}

The regression equation includes 4 terms, obtained from the results of 16 experiments (that is, there are degrees of freedom), so one can assess its adequacy. To do this, we define the dispersion of inadequacy:

$$
S_{\text {adeq }}^{2}=\sum_{1}^{N} y-\tilde{y}^{2} / N-k^{\prime}
$$

where $y$ - actual chip length; $k^{s}$ - number of model coefficients after exclusion of statistically insignificant.

Table III shows the calculation of the variation of the theoretical and calculated values of the chip element length. For this, only statistically significant coefficients are included in the matrix. In accordance with the result of the calculation, we determine:

$$
S_{\text {adeq }}^{2}=654.338 / 16-4=54.528 .
$$

TABLE III. CALCULATION OF VARIANCE OF ADEQUACY

\begin{tabular}{|l|c|c|c|c|c|c|c|}
\hline $\mathbf{N}$ & $\boldsymbol{b}_{\mathbf{0}}$ & $\boldsymbol{b}_{\mathbf{4}}$ & $\boldsymbol{b}_{\mathbf{6}}$ & $\boldsymbol{b}_{\mathbf{8}}$ & $\boldsymbol{y}$ & $\tilde{\boldsymbol{y}}$ & $\boldsymbol{\chi}-\tilde{\boldsymbol{y}} \boldsymbol{\mathbf { z }}$ \\
\hline 1 & + & + & + & + & 39.234 & 29.551 & 93.768 \\
\hline 2 & + & - & - & + & 27.401 & 26.967 & 0.188 \\
\hline 3 & + & + & + & - & 13.238 & 21.466 & 67.704 \\
\hline 4 & + & - & + & - & 11.077 & 6.433 & 21.568 \\
\hline 5 & + & + & - & + & 43.313 & 42.000 & 1.723 \\
\hline 6 & + & + & - & - & 24.887 & 33.916 & 81.521 \\
\hline 7 & + & - & + & - & 9.493 & 6.433 & 9.364 \\
\hline 8 & + & - & - & - & 20.574 & 18.883 & 2.861 \\
\hline 9 & + & + & - & + & 40.470 & 42.000 & 2.342 \\
\hline 10 & + & - & - & + & 24.637 & 26.967 & 5.428 \\
\hline 11 & + & - & + & + & 16.173 & 14.517 & 2.742 \\
\hline 12 & + & - & + & + & 12.153 & 14.517 & 5.590 \\
\hline 13 & + & + & + & - & 19.877 & 21.466 & 2.526 \\
\hline 14 & + & + & + & + & 22.689 & 29.551 & 47.082 \\
\hline 15 & + & + & - & - & 50.158 & 33.916 & 263.807 \\
\hline 16 & + & - & - & - & 12.091 & 18.883 & 46.124 \\
\hline & & & & & & $\Sigma 654.338$ \\
\hline
\end{tabular}

To assess the adequacy of the regression equation, use the Fisher criterion. We define its calculated value and compare it with the table value with a significance level of 0.05 :

$$
F_{P}=\frac{S_{a d e q}^{2}}{S_{y}^{2}}=\frac{54.528}{31.734}=1.718 . F_{0.05 ; 11 ; 3}=8.7
$$

Consequently, at the $5 \%$ level of significance, the regression equation obtained can be used to determine and control the length of the chip element. The regression equation obtained above is written in the coded variables. In connection with its adequacy, we pass to natural variables, using the coding relation [5,9] of the i-th variable for the algebraic polynomial: 


$$
x_{i}=\frac{\tilde{x}_{i}-x_{0_{i}}}{x_{B_{i}}-x_{0_{i}}},
$$

where $x_{i}, \tilde{x}_{i}-$ respectively, the coded and natural designation of the $\mathrm{i}$-th factor; $x_{B_{i}}, x_{O_{i}}$ - respectively, the natural values of the $i$-th factor at the upper and main levels:

$$
x_{0_{i}}=x_{B_{i}}+x_{H_{i}} / 2 \text {, }
$$

where $x_{H_{i}}$ - natural value of the i-th factor at the lower level.

Let us write the coded values of the variables in terms of natural quantities, using the data in Table I:

$$
\begin{gathered}
x_{4}=\frac{t-3}{5-3}=\frac{t-3}{2} ; x_{6}=\frac{\lambda-40}{70-40}=\frac{\lambda-40}{30} ; \\
x_{8}=\frac{\varphi-4.5}{7-4.5}=\frac{\varphi-4.5}{2.5} .
\end{gathered}
$$

The obtained expressions are substituted into the regression equation:

$$
\begin{aligned}
\tilde{y}=24.216+ & 7.517\left(\frac{t-3}{2}\right)-6.225\left(\frac{\lambda-40}{30}\right)+4.042\left(\frac{\varphi-4.5}{2.5}\right)= \\
= & 13.964+3.759 t-0.208 \lambda+1.617 \varphi .
\end{aligned}
$$

\section{CONCLUSION}

Thus, an adequate empirical mathematical model is obtained in the form of an algebraic polynomial. However, it is necessary to note the following circumstances. The variance of the experiment was assessed by fictitious factors. As indicated in [4], effects (twice the coefficient $b_{i}$ ) of fictitious factors are zero only if there is no interaction of factors and the measurements are absolutely accurate. Since the calculated (theoretical) values of the length of the chip element were used to fill the matrix, there are no measurement errors. But the numerical values of the fictitious coefficients are not zero (and the values of the two coefficients are sufficiently large: 1.749 and -2.143). This indicates the possibility of interaction of factors. This is indicated by a rather large amount of the sum of the variations in the theoretical and calculated values $\Sigma 654.338$ (Table III). To a large extent, the adequacy of the regression equation is associated with a rather large variance of experience, determined through the introduced fictitious factors. All this points to the need for more detailed consideration of the degree of influence of factors in the course of further research.

\section{References}

[1] T. Wohlers, Wohlers report 2014: Additivemanufacturingand 3Dprintingstateoftheindustry: Annualworld-wideprogressreport, Wohlers Associates, 2014.

[2] V.F. Bobrov, D.E. Ierusalimskiy. Cutting metals by self-rotating. Mashinostroenie, Moscow, 1972.

[3] P.I. Yascheritsyn, A.V. Borisenko, I.G. Drivotin, V.Ya. Lebedev. Rotational cutting of materials. Science and Technology, Minsk, 1987.

[4] V.G. Shalamov, S.D. Smetanin, "Obtaining the chip element by rotary milling”, Technological support of machine-building productions: Sat. sci. tr. I intern. extramural scientific-technical. conf., pp. 587-591, 2014.

[5] Yu.P. Adler, E.V. Markova, Yu.V. Granovsky. Planning an experiment in the search for optimal conditions. Publishing house "Science", Moskow, 1976.

[6] F.S. Novik, Ya.B. Arsov. Optimization of the processes of metal technology by the methods of experiment planning. Mechanical Engineering, Moskow, 1980.

[7] A.A. Spiridonov, I.G. Vasiliev. Planning an experiment in the study and optimization of technological processes: a textbook. Publication of UPI, Sverdlovsk, 1975.

[8] K. Hartman, E. Letskiy, V. Shefer, etc. Planning an experiment in the study of technological processes. Mir publishing house, Moskow, 1977.

[9] V.G. Shalamov. Mathematical Modeling in Metal Cutting: a textbook. Publishing house of SUSU, Chelyabinsk, 2007. 